\title{
La precariedad de las democracias en América Latina: una mirada desde la Doctrina Social de la Iglesia
}

\author{
Beatriz Eugenia Campillo Vélez ${ }^{1}$
}

Recibido en 22 de mayo de 2017, aceptado el 27 de junio de 2017

\begin{abstract}
Resumen
El texto intenta recordar las bases de lo que es una auténtica democracia, contrastándola con los procesos que se han vivido en América Latina, especialmente desde la Guerra Fría y la Globalización. Se trata de un recorrido que nos hemos propuesto presentar desde la Doctrina Social de la Iglesia, pues sus documentos no solo reflejan la realidad de la región, sino que también aportan elementos de juicio para la transformación social, mostrándose críticos frente a algunos aspectos, pero también esperanzadores al recordar el sentido de la comunidad política.
\end{abstract}

Palabras clave

Democracia, América Latina, Doctrina Social, Guerra Fría, Globalización.

\begin{abstract}
The text tries to remember the bases of what is a true democracy, contrasting it with the processes that have been experienced in Latin America, especially since the Cold War and Globalization. It's a road that we have proposed to present from the Social Doctrine of the Church, because its documents not only reflect the reality of the region, but also provide elements of judgment for social transformation, showing some critical aspects, but also hopeful to the Remember the meaning of the political community.
\end{abstract}

Keywords

Democracy, Latin America, Social Doctrine, Cold War, Globalization.

1. Magister en Filosofía y Politóloga de la Universidad Pontificia Bolivariana de Medellín, Colombia. beatriz.campillo@upb.edu.co 
La democracia en América Latina ha vivido procesos difíciles en su construcción, procesos que aún no terminan de configurarse y nos atrevemos a afirmar que algunos apenas comienzan, por tanto, los retos son muchos. En el presente texto pretendemos recordar las bases de lo que implica una auténtica democracia y lo que ella exige, para posteriormente acercarnos a la historia que ha marcado el desarrollo de este sistema de gobierno en América Latina, haremos una breve referencia a la situación de la llamada "modernización sin modernidad" que inicia desde el periodo de las independencias y que marcará los procesos políticos hasta nuestros días. Pero de manera especial centraremos nuestro esfuerzo en describir las dinámicas que ha vivido el subcontinente en dos momentos particulares: primero, el orden internacional de la Guerra Fría marcado en nuestro caso por las dictaduras militares y por los diferentes movimientos guerrilleros; y el segundo, el actual orden internacional de la globalización, donde veremos una democracia más consolidada en sus formas, pero advertiremos su precariedad debido especialmente a la amenaza de los neopopulismos.

Esta reflexión como lo expresamos en el título hemos querido hacerla a la luz de la Doctrina Social de la Iglesia, especialmente desde de la Constitución pastoral Gaudium et Spes, que tomaremos como punto de partida, por lo que solo nos referiremos a los documentos postconciliares y con mayor énfasis relacionaremos aquellos que han sido producto de las Conferencias generales del episcopado latinoamericano. De esta manera nuestro camino será evidenciar cómo los documentos no solo han reflejado la realidad de la región, sino que también han aportado elementos de juicio para transformar los procesos mostrándose críticos frente a algunos aspectos, pero también esperanzadores al recordar el sentido de la comunidad política y servir de medio para el fortalecimiento del gran protagonista en las democracias: el ciudadano, con miras al bien común.

\section{Una aproximación a la democracia}

Es importante recordar que una democracia no se circunscribe exclusivamente a la participación en términos electorales (voto, candidatos, sufragantes, campañas, etc.), sino que debe llegar a convertirse en un modo de vida, una cultura, una forma de relacionarnos, para lo cual es necesario partir del reconocimiento de unos postulados básicos que podríamos señalar como los siguientes²:

- El postulado de la Racionalidad: Se trata de un presupuesto antropológico, es decir, partimos de la idea de que los seres humanos estamos dotados de la capacidad para evaluar por medio de la razón las diferentes propuestas, y decidir cuál es la mejor opción, o al menos, cuál es la menos mala. Si se trata de una decisión racional esto supone que el ciudadano antes de

2. Aquí seguiremos los postulados señalados por el profesor José Olimpo Suárez Molano en su libro "Syllabus sobre filosofía política". 
tomarla previamente ha estudiado a fondo las distintas alternativas, las ha comparado y después de esa ponderación se ha decantado por una de ellas. En otras palabras, podríamos decir que su decisión es el camino que él le está sugiriendo a la sociedad seguir porque estima es el más conveniente para todos, pues la racionalidad implica también suponer que la persona intentará seguir la regla de oro ético-moral de "buscar el bien y evitar el mal".

Cuando el ejercicio no se hace de forma racional sino que la decisión fue realizada sin reflexión o por una motivación meramente emocional o inspirada en fines calculadores que buscan una ventaja personal, estaremos frente a la llamada "oclocracia" (gobierno de la muchedumbre) y no frente a una auténtica democracia.

Surge allí pues el problema real que ha afectado a las democracias, y en particular a América Latina, y es que no contamos con ciudadanos bien formados, que puedan asumir responsablemente el poder que como soberanos tienen $^{3}$, ya que generalmente no conocen las normas que los rigen - y que ellos mismos crearon-, ni suelen preocuparse por alcanzar una instrucción suficiente frente a los temas donde deben pronunciarse. En otras palabras, en nuestras democracias nos encontramos partiendo de un equívoco -algo que ya advertía Platón-, suponemos que a quien le preguntamos está facultado para darnos una respuesta meditada y no producto de un impulso, por lo que apelamos al criterio de mayorías suponiendo también ingenuamente que son más los que tendrán esa preparación de sabernos guiar. Cuando en realidad la experiencia nos muestra que tenemos pueblos con bajo nivel educativo y que la indiferencia es alta. Habrá que decir entonces que el problema no estriba en el sistema democrático, sino que este parte de unos estándares muy altos de exigencia, de responsabilidad de los ciudadanos; y que dichos estándares tal vez no los tenemos.

- El postulado del Autogobierno: es la idea según la cual las personas suelen acatar mejor las decisiones cuando ellas mismas las toman. No implica

\footnotetext{
3. Muchos incluso desconocen el tenerlo, desde mi experiencia docente he formulado con regularidad la pregunta de ¿quién es el soberano en una democracia? a distintos grupos (algunos en alto grado de formación académica), y aunque siempre hay alguien que responde que es el pueblo, también es frecuente escuchar previamente en el público alusiones al presidente o al congreso como si de una monarquía o una aristocracia se tratara; cuando no es que aparece en el auditorio la actitud de silencio. Por lo que iniciar a fortalecer la democracia con un acercamiento pedagógico a los conceptos más básicos, podría ayudar a ganar apropiación y sensibilizar sobre la importancia de tener ciudadanos activos que fortalezcan la institucionalidad y sean menos pasionales. Al respecto son interesantes los talleres, foros, cursos y diplomaturas que desde las diversas instituciones educativas y sociales se realizan. A manera de ejemplo cito el caso de la Universidad Pontificia Bolivariana, en Medellín, donde además de los programas de formación en pregrado y postgrado, se abren espacios de discusión en eventos públicos, se hace también formación mediante sus programas radiales, puntualmente tenemos la experiencia del programa "De las cosas nuevas" que dirige el grupo de Investigación Diké sobre Doctrina social de la Iglesia. Así mismo está el Observatorio de ética, política y sociedad cuyo impacto social ya es reconocido ("IES, con más proyección social" http://www.elcolombiano.com/ies-con-mas-proyeccion-social-MC2602934).

Adicional a ello la Arquidiócesis de Medellín cuenta con medios de comunicación propios que le han permitido brindar elementos de reflexión en los debates locales, nacionales e internacionales como desarrollo de las líneas pastorales sugeridas por el CELAM.
} 
esto que sean infalibles, pero sí genera un mayor compromiso y una mayor aceptación que cuando estas vienen impuestas por unos pocos o por uno solo, en tanto en las democracias se parte de la idea de que entre todos será posible perfeccionar las propuestas, esto significa que el debate deberá estar centrado en las ideas y no en el ataque personal.

- El postulado de la Igualdad: En toda democracia moderna es necesario que los ciudadanos estén en igualdad de condiciones al menos frente a la ley, esto significa no que sean iguales en tanto su condición física o intelectual, sino iguales en tanto el poder elegir y ser elegidos, igualdad para que su voto valga lo mismo que el de cualquier otro, igualdad para que nadie quede excluido en razón de su religión, sexo, raza, condición socio-económica, posición política, sino que sean iguales en tanto ciudadanos. Igualdad para que no exista esclavitud.

Esta última idea implica que además todo ciudadano debería ser consciente del poder que tiene, que nadie debería ser tan pobre o sentirse tan excluido que no le importe vender su voto a cambio de cualquier prebenda, y que nadie tampoco se crea con el derecho de comprar conciencias.

- El postulado de la Libertad: Los seres humanos somos seres libres, no estamos determinados, por tanto conservar y hacer respetar esta condición en la política no solo dignifica a la persona sino que le permite tomar decisiones sin coacción externa y por tanto hacerse responsable de ellas.

Isaiah Berlin realizó un aporte importante al respecto diferenciando con claridad la doble dimensión de la libertad, lo que él denominó "libertad positiva" (posibilidad de hacer) y "libertad negativa" (posibilidad de no hacer o no ser intervenido), ambas libertades son fundamentales en toda democracia, por ejemplo: así como tengo la posibilidad de emitir mi voto, debo también tener la posibilidad abstenerme ${ }^{4}$, de igual manera asistir o no a una marcha, pronunciarme o no frente a alguna situación en un medio público deberá ser algo que no venga impuesto por el Estado y debe ser tan respetable que no pueda generar sospecha ni tampoco censura el actuar de una forma o de la otra. Obviamente partir de estas ideas exige ubicarnos en un plano de madurez democrática alta, donde las razones que se argumenten en un sentido o en otro deben ser privativas del individuo a quien consideramos en términos kantianos un mayor de edad -el ciudadano- y por tanto suponemos que ha hecho un ejercicio racional para tomarlas.

Partiendo de lo anterior es claro que toda democracia necesita tener como criterio de legitimidad el profundo respeto a los Derechos Humanos, y como garantía de ello se hace necesario contar a su vez con unos prepuestos como lo es la institucionalidad, representada en el profundo respeto al Estado de Derecho, valga aclarar que nos referimos a aquel Estado en el que las normas jurídicas

4. Al respecto hay una discusión importante frente al voto obligatorio que no abordaremos. Sin embargo digamos que la abstención también manda un mensaje que también debe ser tenido en cuenta. 
están por encima de todos, incluyendo al gobernante quien debe ver su poder limitado y controlado por el soberano, que en toda democracia tiene que ser el pueblo como constituyente primario, quien no solo expresa su voluntad en la Constitución Política, sino que debe contar con los mecanismos suficientes para participar, controlar y hacer valer sus derechos, para lo cual se requiere como hemos dicho ciudadanos bien formados y activos. ${ }^{5}$

Lo dicho hasta el momento está en completa armonía con los principios de la Doctrina Social de la Iglesia. Es claro que la democracia debe estar orientada hacia el bien común e inspirado por la solidaridad, ya que si bien las decisiones se toman por mayorías no deben ir en perjuicio de las minorías, por lo cual no puede darse el esquema de "amigo-enemigo" o lo que es igual la lógica de que "el que no está conmigo, está contra mí". En una democracia tiene que existir el derecho al disenso por las vías pacíficas, la posibilidad de argumentar en contrario, debatir, proponer, pero así mismo, como lo hemos dicho se necesitan unas bases sólidas que la sostengan; de esta manera no solo se respeta el principio de participación, sino que se tiene claro que el respeto por la dignidad de la persona humana (los derechos humanos), es el eje transversal que debe iluminar el ejercicio democrático y servir de limite a este. Así se rompe el esquema de "democratización" - absolutizar la democracia- que también resulta altamente peligroso en tanto lleva a relativismos dogmáticos, en otras palabras, al supuesto de afirmar que todo es susceptible a ser decidido por la mayoría, olvidando que una democracia auténtica, debe partir de unos principios fundamentales, no sea que confundiéndola con el mero procedimiento, los formalismos, terminemos avalando bajo sus mecanismos practicas abiertamente antidemocráticas. Es el caso donde hay votaciones pero solo existe un partido político o un solo candidato representa todas las fuerzas, pero también aplica cuando sometemos a decisión democrática cuestiones que encarnan directamente la violación a los derechos humanos, tales como cuando se pone en duda el estatus mismo de persona de algunos seres humanos al mejor estilo del régimen nazi. 6

5. "La autoridad pública tiene la misión de propiciar y fortalecer la creación de mecanismos de participación y de legítima representación de la población, o si fuera necesario, la creación de nuevas formas. Queremos insistir en la necesidad de vitalizar y fortalecer la organización municipal y comunal, como punto de partida hacia la vida departamental, provincial, regional y nacional." (Medellín 16), pero la Iglesia también tiene una responsabilidad, de allí que se señale que "La acción pastoral de la Iglesia estimulará a todas las categorías de ciudadanos a colaborar en los planes constitutivos de los gobiernos y a contribuir, también por medio de la crítica sana dentro de una oposición responsable; al progreso del bien común." (Medellín 21)

6. En este punto particular no entraremos, pero hay algunos elementos desarrollados al respecto en la ponencia que presenté en el congreso internacional de la Fundación Vaticana Joseph Ratzinger - Benedicto XVI, titulada: "El desafío de la verdad en la construcción de la civilización de la vida". Publicada en el libro de memorias "EL RESPETO A LA VIDA: Un camino para la paz". Medellín: Universidad Pontificia Bolivariana y Editorial San Pablo, 2014. 
Para comprender aún mejor estos fenómenos que hemos empezado a esbozar y que nos llevan a plantear la precariedad de nuestra democracia, hagamos un acercamiento de tipo histórico contrastándolo a su vez con los llamados que han surgido desde los distintos documentos que enriquecen el pensamiento social de la Iglesia.

\section{La democracia latinoamericana}

\section{A. Una "modernización sin modernidad"}

Nuestra región ha vivido lo que algunos autores denominan una "modernización sin modernidad", es decir, unos procesos forzados que nos llevan a tener en la actualidad las mismas estructuras que cualquier país europeo, pero sin las bases que ellos tienen, sin historia, sin comprensión. Huelga decir que lo heredamos o nos lo impusieron, pero a fin de cuentas no dimos ese paso de "mayoría de edad" de pensar por nosotros mismos.

Es así como mientras que en la construcción del Estado Moderno se puede hacer una historia larga en Europa de luchas, conquistas, enfrentamientos para llegar a la configuración actual, una historia que abarca imperios, principados, feudalismos, etc. donde la comprensión de la importancia de la separación de poderes sumado a la idea misma de los Estados de Derecho vino marcada por la experiencia de monarquías absolutas y hasta el discurso de los Derechos Humanos fue el resultado de una larga cadena de hechos sangrientos. A nosotros los latinoamericanos nos llegaron en gran medida estas ideas por exportación, alguien había viajado y se inspiraba en esos modelos, alguien -como Antonio Nariño- traía una traducción de la Declaración de los Derechos del Hombre y del Ciudadano, o se copiaban las Constituciones de otros lugares y de esa forma fuimos intentando organizar nuestras naciones (aunque aún nos preguntamos si somos o no una nación). El profesor Josef Thesing lo relata así:

\footnotetext{
“Esto comenzó con las constituciones, ensambladas a partir de otros textos; los textos constitucionales de los nuevos estados independientes usaron como fuentes la constitución norteamericana de 1787, la constitución francesa de 1791 y la constitución española de Cádiz de 1812. Pero con ello comienza uno de los problemas fundamentales de los sistemas políticos de América Latina: la contradicción entre Constitución y constitucionalidad real: es decir, los textos constitucionales no orientan la realidad política. Después se genera un largo ciclo de golpes de Estado y períodos alternos de gobiernos democráticos formales, los cuales, casi siempre engendraron nuevos textos constitucionales. Pero poco cambió en la problemática de fondo reseñada, porque no se modificaron las estructuras de poder dominantes."
}

7. Thesing, Josef. Democracia y Estado de Derecho en América Latina. En: La cuestión social, México, Instituto Mexicano de Doctrina Social Cristiana, año 8, no. 1 (ene.-mar., 2000), p. 65. Recuperado de: http://media.wix.com/ugd/768ef7_0171f2f3349b47f5b36e77f8b5e84c2e.pdf 
No es gratuito entonces que con el pasar del tiempo también hayamos observado que nos cuesta comprender la lógica de institucionalidad que supone el Estado Moderno (El imperio de la ley -derechos, deberes, garantías, libertades-, la separación de poderes públicos, los órganos de control, el monopolio de la fuerza, la necesidad de partidos fuertes - representativos-, etc.), por lo que hemos vivido una larga historia de corrupción, mesianismos, caudillismos, populismos e incluso hoy, neopopulismos. Una exaltación de los personalismos que lejos de ver en el Estado la forma de hacer un proyecto común a largo plazo, creen que deben liberar al pueblo de una estructura que experimentan como nociva, todo porque ni ellos - los gobernantes personalistas- ni buena parte del pueblo han entendido de qué se trata, ni para qué sirve.

\section{B. Guerra Fría: América latina entre Dictaduras y Guerrillas}

La historia del siglo XX estuvo marcada por fuertes dictaduras militares, y como la mayor contradicción, se trataba de unas dictaduras que decían defender la democracia, ya que el pueblo estaba amenazado por un enemigo mayor "el comunismo" -encarnado en las guerrillas- y desde allí legitimaban su discurso, mientras al mismo tiempo bajo una óptica realista nos encontrábamos con los más grandes atropellos. Claramente el comunismo era una amenaza - no solo las prácticas de las guerrillas eran altamente violentas, sino que además como sistema ha probado suficientemente tener amplios problemas y ser severamente represorpero la solución por la vía de dictaduras tampoco era la salida. Lastimosamente esos desmanes con el tiempo han contribuido a una estigmatización de la fuerza pública que algunos siguen viendo con desconfianza a pesar de los grandes avances que en defensa de derechos humanos se han tenido.

En este contexto de la Guerra Fría fue presentada en 1965, la constitución pastoral Gaudium et Spes "sobre la Iglesia en el mundo actual” como resultado del Concilio Vaticano II, pero así mismo es un documento permeado por las situaciones políticas del orden internacional que en ese momento histórico se vivía. Las disputas ideológicas entre los bloques enfrentados, las amenazas de un ataque nuclear, sumado a las constantes guerras periféricas -incluyendo el caso latinoamericano- marcan su discurso.

En este sentido el capítulo IV dedica sus reflexiones en torno a "la vida en la comunidad política", advierte que se trata de una época de transformaciones, especialmente en las estructuras e instituciones. Destaca de manera especial el papel protagónico que van ganando los derechos y deberes en la búsqueda del bien común, tanto en la relación entre ciudadanos como con el gobernante, y cómo cada vez más se toma conciencia frente a la importancia de la dignidad humana al punto que se busca que el ordenamiento jurídico y político brinde protección a la persona humana y se garanticen sus libertades "como son el derecho de libre reunión, de libre asociación, de expresar las propias opiniones y de profesar privada y públicamente la religión. Porque la garantía de los derechos de la persona es condición necesaria para que los ciudadanos, como 
individuos o como miembros de asociaciones, puedan participar activamente en la vida y en el gobierno de la cosa pública." (GS73)

Sin lugar a dudas la crítica más fuerte se dirige al comunismo, la forma en la que se restringen las libertades más básicas de los seres humanos ${ }^{8}$. Ahora bien, aunque no se puede entender este discurso como un apoyo al bloque occidental liderado por los Estados Unidos - porque también se le critica-, es cierto que de fondo se recogen y defienden los postulados básicos de la cultura occidental, aquellos que llevan a reafirmar la democracia como un buen sistema de gobierno y los derechos humanos como su fundamento, tesis que son más cercanas al liberalismo que al comunismo9. Mientras se deja claro que "Se reprueban también todas las formas políticas, vigentes en ciertas regiones, que obstaculizan la libertad civil o religiosa, multiplican las víctimas de las pasiones y de los crímenes políticos y desvían el ejercicio de la autoridad en la prosecución del bien común, para ponerla al servicio de un grupo o de los propios gobernantes." (GS73)

8. “Opuesto al liberalismo económico en su forma clásica y en lucha permanente contra sus injustas consecuencias, el marxismo clásico sustituye la visión individualista del hombre por una visión colectivista, casi mesiánica, del mismo. La meta de la existencia humana se pone en el desarrollo de las fuerzas materiales de producción. La persona no es originalmente su conciencia; está más bien constituida por su existencia social. Despojada del arbitrio interno que le puede señalar el camino para su realización personal, recibe sus normas de comportamiento únicamente de quienes son responsables del cambio de las estructuras socio-político-económicas. Por eso, desconoce los derechos del hombre, especialmente el derecho a la libertad religiosa, que está a la base de todas las libertades" (Puebla, 313)

9. Este pensamiento también fue reflejado por latinoamericanos en distintos medios, a manera de ejemplo citemos una de las críticas que aparecen desde el séptimo arte cuando el comediante mexicano Mario Moreno "Cantinflas" en su película "Su excelencia” (1966) se refiriere al comunismo: "hablan de libertades humanas, pero yo les pregunto: ¿existen esas libertades en sus propios países? Dicen defender los Derechos del Proletariado pero sus propios obreros no tienen siquiera el derecho elemental de la huelga, hablan de la cultura universal al alcance de las masas pero encarcelan a sus escritores porque se atreven a decir la verdad, hablan de la libre determinación de los pueblos y sin embargo hace años que oprimen una serie de naciones sin permitirles que se den la forma de gobierno que más les convenga ¿Cómo podemos votar por un sistema que habla de dignidad y acto seguido atropella lo más sagrado de la dignidad humana que es la libertad de conciencia eliminando o pretendiendo eliminar a Dios por decreto? No, señores representantes, yo no puedo estar con los Colorados, o mejor dicho con su modo de actuar; respeto su modo de pensar, allá ellos, pero no puedo dar mi voto para que su sistema se implante por la fuerza en todos los países de la tierra" En cuanto al capitalismo refiere lo siguiente "ustedes también tienen mucha culpa de lo que pasa en el mundo, ustedes también son medio soberbios, como que si el mundo fueran ustedes y los demás tienen una importancia muy relativa, y aunque hablan de paz, de democracia y de cosas muy bonitas, a veces también pretenden imponer su voluntad por la fuerza, por la fuerza del dinero. Yo estoy de acuerdo con ustedes en que debemos luchar por el bien colectivo e individual, en combatir la miseria y resolver los tremendos problemas de la vivienda, del vestido y del sustento. Pero en lo que no estoy de acuerdo con ustedes es la forma que ustedes pretenden resolver esos problemas, ustedes también han sucumbido ante el materialismo, se han olvidado de los más bellos valores del espíritu pensando sólo en el negocio, poco a poco se han ido convirtiendo en los acreedores de la Humanidad y por eso la Humanidad los ve con desconfianza." Delgado, Miguel M. (Director). Película: “Su excelencia”. Productora: Posa Films. México: 1967. 
Ahora bien, insistimos en que estas críticas no pueden interpretarse como un aval al pensamiento liberal, al que se le critica especialmente su modelo económico y político por su lógica individualista y utilitarista ${ }^{10}$, centrado en el capital, donde las cosas parecieran ser más importantes que las personas y se olvida el sentido de solidaridad, por lo que se hace el llamado a "una mayor colaboración a fin de que todos los ciudadanos, y no solamente algunos privilegiados, puedan hacer uso efectivo de los derechos personales" (GS73). De tal manera que la relación que señalamos de "cierta afinidad", solamente puede ser entendida como una forma de intentar rescatar lo positivo que ha aportado nuestra cultura occidental - pero aquella que viene desde Grecia y Roma- y superar los maniqueísmos ideológicos que enfrascaron el mundo durante las décadas de la Guerra Fría.

Estas líneas generales que se aportaban desde el Concilio Vaticano II se vieron complementadas y contextualizadas al ámbito latinoamericano con la II Conferencia General del Episcopado Latinoamericano celebrado en Medellín, Colombia en 1968. En la inauguración dada en Bogotá, “Pablo VI insistió en promover la justicia y la paz pero alertó ante la violencia y el odio del marxismo ateo y de la rebelión sistemática"11, lo que de nuevo alude al orden internacional de la Guerra Fría, y a la revolución cultural que inició el mayo del 68 francés.

El documento conclusivo que tiene por título "La Iglesia en la actual transformación de América Latina a la luz del Concilio”, resalta en materia política que existe una falta de integración sociocultural y que esta "falta de adaptación a la idiosincrasia y a las posibilidades de nuestra población, origina, a su vez, una frecuente inestabilidad política y la consolidación de instituciones puramente formales."(Medellín 2), por tanto se necesita una reforma, pues recordando que la autoridad política y sus decisiones deben orientarse hacia el bien común se denuncia que "En Latinoamérica tal ejercicio y decisiones con frecuencia aparecen apoyando sistemas que atentan contra el bien común o favorecer a grupos privilegiados." (Medellín 16), por lo que se recuerda que "la autoridad deberá asegurar eficaz y permanentemente a través de normas jurídicas, los derechos y libertades inalienables de los ciudadanos y el libre funcionamiento de las estructuras intermedias." (Medellín 16)

Posteriormente en Puebla, México (1979), aparece de nuevo una orientación frente al orden internacional que se estaba viviendo, en el apartado sobre las

10. "Al servicio de la sociedad del consumo, pero proyectándose más allá de la misma, el liberalismo económico, de praxis materialista, nos presenta una visión individualista del hombre. Según ella, la dignidad de la persona consiste en la eficacia económica y en la libertad individual. Encerrada en sí misma y aferrada frecuentemente a un concepto religioso de salvación individual, se ciega a las exigencias de la justicia social y se coloca al servicio del imperialismo internacional del dinero, al cual se asocian muchos gobiernos que olvidan sus obligaciones en relación al bien común." (Puebla 312) 11. Carlos Augusto MESA POSADA, Medellín 1968. AHIg 5 (1996). P. 418. dialnet.unirioja.es/descarga/ articulo/1203781.pdf 
"Visiones inadecuadas del hombre en América Latina" se hace referencia de manera expresa al "estatismo":

\begin{abstract}
“Menos conocida pero actuante en la organización de no pocos gobiernos latinoamericanos, la visión que podríamos llamar estatista del hombre tiene su base en la teoría de la Seguridad Nacional. Pone al individuo al servicio ilimitado de la supuesta guerra total contra los conflictos culturales, sociales, políticos y económicos y, mediante ellos, contra la amenaza del comunismo. Frente a este peligro permanente, real o posible, se limitan, como en toda situación de emergencia, las libertades individuales y la voluntad del estado se confunde con la voluntad de la nación. El desarrollo económico y el potencial bélico se superponen a las necesidades de las masas abandonadas. Aunque necesaria a toda organización política, la Seguridad Nacional vista bajo este ángulo se presenta como un absoluto sobre las personas; en nombre de ella se institucionaliza la inseguridad de los individuos." (Puebla 314)
\end{abstract}

La crítica se centra en la situación que América Latina vivía especialmente con las dictaduras militares impulsadas bajo la Teoría Geopolítica de los Estados Unidos denominada "Doctrina de Seguridad Nacional", no hay que olvidar experiencias como las vividas con Videla en Argentina (1976-1981), Bordaberry en Uruguay (1973-1976), Pinochet en Chile (1973-1990), Bouterse en Surinam (1982-1988), Banzer en Bolivia (1971-1978), Stroessner en Paraguay (1954-1989), Trujillo en República Dominicana (1930-1961), Velasco en Perú (1968-1975), Rodríguez en Ecuador (1972-1976), Rojas en Colombia (1953-1957), Somoza en Nicaragua (1936-1956), y Noriega en Panamá (1983-1989). Claramente unas experiencias fueron más duras que otras, y cabe anotar que algunos prolongaron la forma de gobierno dictatorial más allá de los años que hemos señalado, bien porque crearon sus propias "dinastías", o bien porque los que lo sucedieron hacían un remedo de democracia, que aunque conservaba sus formas puede afirmarse que se trataban de auténticas dictaduras civiles ${ }^{12}$. A lo mencionado habrá que sumar que existían colaboración entre países, tanto para la instrucción donde la experiencia más representativa es la Escuela de las Américas, que ayudó a adoctrinar los líderes militares de la región; como para ejercer controles tan extremos que a menudo incluían la tortura y la desaparición, de allí el ejemplo más representativo es la Operación Cóndor en el cono sur.

Este llamado “terrorismo de Estado" que consiste en hacer un uso indebido de la fuerza, realizar censuras, espionaje, desapariciones, tortura, muertes selectivas, genocidios, etc. también fue condenado de manera expresa en el documento de Puebla: “Ante la deplorable realidad de violencia en América

12. Es el caso colombiano con el Frente Nacional. Para ampliar puede leerse el artículo “El Frente Nacional y su naturaleza antidemocrática”, escrito por Esteban Mesa García, publicado en la Revista Facultad de Derecho y Ciencias Políticas. Vol. 39, No. 110 / p. 157-184. Medellín - Colombia. EneroJunio de 2009. 
Latina, queremos pronunciarnos con claridad. La tortura física y sicológica, los secuestros, la persecución de disidentes políticos o de sospechosos y la exclusión de la vida pública por causas de las ideas, son siempre condenables. Si dichos crímenes son realizados por la autoridad encargada de tutelar el bien común, envilecen a quienes los practican, independientemente de las razones aducidas." (Puebla 531)

Ahora bien, el único lugar donde triunfó la "Revolución" fue en Cuba, la cual también hay que contarla como dictadura militar ya que, aunque diga ser de izquierda sus prácticas eran exactamente las mismas de las que hemos mencionado. Pero sería un error histórico afirmar que en los demás Estados solo se dieron violaciones por parte de representantes de la "derecha", pues así como EEUU intervenía para mantener su zona de influencia, la URSS se encargaba de patrocinar tanto en lo económico como en lo político diversos grupos guerrilleros que ponían en serios aprietos la seguridad del continente, pues no solo amenazaban con tomarse el poder con la "combinación de todas las formas de lucha", sino con cambiar las estructuras democráticas que mal que bien funcionaban; ante estos actos también la Iglesia expresó su condena ${ }^{13}$. Sin embargo, digamos que es tan distinta la visión de uno y otro lado que con todo y su horror los países que vivieron las dictaduras militares desde la década de los 80's hicieron el tránsito a la democracia, mientras que en Cuba permanece la dictadura y en la última década tras el fenómeno Chávez, se ha visto no solo fortalecida, sino también legitimada e incluso aparecen conductas similares en países donde lo creíamos superado.

Es así como Puebla advierte un deterioro en el cuadro político-social, señala que "se experimenta el peso de crisis institucionales y económicas y claros síntomas de corrupción y violencia” (509), que debemos resaltar no han cesado, pero además declara que "dicha violencia es generada y fomentada, tanto por la injusticia, que se puede llamar institucionalizada en diversos sistemas sociales, políticos y económicos, como por las ideologías que la convierten en medio para la conquista del poder". (510). Y vuelve a recalcar que "Esto último provoca, a su vez, la proliferación de regímenes de fuerza, muchas veces inspirados en la ideología de la Seguridad Nacional" (511). Para finalmente llegar a señalar que, aunque se intente instrumentalizar su mensaje, el papel de la Iglesia es el de discernir e iluminar, desde el Evangelio y su enseñanza social, la vida política del continente. Por eso su reflexión no está orientada al apoyo de una ideología, no trata de alinearse y de hecho critica a los Ministros que en su nombre han asumido esta actitud que es contraria a su misión, la cual implica recordar el

13. "Con igual decisión la Iglesia rechaza la violencia terrorista y guerrillera, cruel e incontrolable cuando se desata. De ningún modo se justifica el crimen como camino de liberación. La violencia engendra inexorablemente nuevas formas de opresión y esclavitud, de ordinario más graves que aquéllas de las que se pretende liberar. Pero, sobre todo, es un atentado contra la vida que sólo depende del Creador. Debemos recalcar también que cuando una ideología apela a la violencia, reconoce con ello su propia insuficiencia y debilidad." (Puebla 532) 
sentido mismo de la dimensión política en el hombre, que no debería ser otra que la de lograr una convivencia pacífica que permita buscar el bien común, baste recordar que este incluso es el sentido mismo de la creación del Estado. Desde esa perspectiva está claro que "La política partidista es el campo propio de los laicos (GS 43). Corresponde a su condición laical el constituir y organizar partidos políticos, con ideología y estrategia adecuada para alcanzar sus legítimos fines." (Puebla 524), mientras que a "Los Pastores, por el contrario, puesto que deben preocuparse de la unidad, se despojarán de toda ideología político-partidista que pueda condicionar sus criterios y actitudes. Tendrán, así, libertad para evangelizar lo político con Cristo, desde un Evangelio sin partidismos ni ideologizaciones." (Puebla 526).

\section{Término de la Guerra Fría e inicio de la Globalización}

Como hemos afirmado, desde la década de los 80's América latina ha realizado una transición a la democracia, y podríamos decir que gracias al triunfo del bloque occidental, después de la caída del muro de Berlín hemos asistido a una exaltación de la democracia en el mundo, al igual que el discurso de los Derechos Humanos. ${ }^{14}$

Llama la atención que en documentos como la Gaudium et Spes, la Populorum Progressio y el documento conclusivo de Medellín no se haga ninguna mención directa a la democracia, aunque en su espíritu se deje ver que coincide en los principios fundamentales y que de alguna forma la respalda. En Puebla ya se hace mención al término, pero no se asocia a la política, sino a la educación, probablemente ello responda al momento histórico, pues de asumir abiertamente sus banderas se hubiera podido entender como un respaldo al bloque occidental. Después de la caída del muro de Berlín las referencias son directas, tanto que el Compendio de la Doctrina Social de la Iglesia lo incluye como un subtítulo en el capítulo IV que versa sobre sus principios: "Participación y democracia", y en el capítulo VIII hay un título dedicado específicamente a ella "el sistema de la democracia"; pero de manera más clara el Papa Juan Pablo II en su Encíclica "Sollicitudo Rei Socialis" expresa:

\footnotetext{
“Otras Naciones necesitan reformar algunas estructuras y, en particular, sus instituciones políticas, para sustituir regímenes corrompidos, dictatoriales o autoritarios, por otros democráticos y participativos. Es un proceso que, es de esperar, se extienda y consolide, porque la « salud » de una comunidad política -en cuanto se expresa mediante la libre participación y responsabilidad de todos los ciudadanos en la gestión pública, la seguridad del derecho, el respeto y la promoción de los derechos humanos- es condición necesaria y garantía segura para el desarrollo de « todo el hombre y de todos los hombres »." (44)
}

\footnotetext{
14. Aunque también es cierto que recientemente, producto así mismo de la globalización, hemos experimentado un "choque de civilizaciones" al comprobar que en otras latitudes se tienen manifiestamente principios muy diversos a los que defiende occidente.
} 
De esta manera retoma las enseñanzas de Pablo IV, pero las actualiza al contexto de final de la Guerra fría y se convierte en un preámbulo a la globalización, lo mismo hará en Centesimus Annus, donde además dedica un capítulo al análisis de lo sucedido en el año 1989 y asevera que "La Iglesia aprecia el sistema de la democracia, en la medida en que asegura la participación de los ciudadanos en las opciones políticas y garantiza a los gobernados la posibilidad de elegir y controlar a sus propios gobernantes, o bien la de sustituirlos oportunamente de manera pacífica. Por esto mismo, no puede favorecer la formación de grupos dirigentes restringidos que, por intereses particulares o por motivos ideológicos, usurpan el poder del Estado." (46) y sin reservas manifiesta que "Una auténtica democracia es posible solamente en un Estado de derecho y sobre la base de una recta concepción de la persona humana. Requiere que se den las condiciones necesarias para la promoción de las personas concretas, mediante la educación y la formación en los verdaderos ideales, así como de la «subjetividad» de la sociedad mediante la creación de estructuras de participación y de corresponsabilidad" (46). Y sentencia que "Después de la caída del totalitarismo comunista y de otros muchos regímenes totalitarios y de «seguridad nacional», asistimos hoy al predominio, no sin contrastes, del ideal democrático junto con una viva atención y preocupación por los derechos humanos." (47), ideas que se han reforzado en las Encíclicas posteriores tanto de Benedicto XVI como de Francisco.

En el contexto latinoamericano en el documento conclusivo de Santo Domingo (1992), se incluye un subtítulo sobre "el orden democrático", donde se recogen las ideas de Juan Pablo II y se destaca el papel de la Iglesia en la región para sentar las bases de "una convivencia basada en el diálogo y el respeto a la persona humana” (190), igualmente se establecen como líneas pastorales el crear las condiciones para formar a los laicos con miras a una actuación política que sirva a la comunidad y que perfeccione la democracia, para lo cual también se busca orientar "la familia, a la escuela y a las diversas instancias eclesiales, para que eduquen en los valores que fundan una auténtica democracia”. (193)

En cuanto a los gobernantes se denuncia el aumento de la corrupción "Hay un mal manejo de los recursos económicos públicos; progresan la demagogia, el populismo, la «mentira política» en las promesas electorales; se burla la justicia, se generaliza la impunidad y la comunidad se siente impotente e indefensa frente al delito. Con ello se fomenta la insensibilidad social y el escepticismo ante la falta de aplicación de la justicia, se emiten leyes contrarias a los valores humanos y cristianos fundamentales. No hay una equitativa distribución de los bienes de la tierra, se abusa de la naturaleza y se daña el ecosistema." (233)

En este sentido debemos destacar que, aunque se experimenta optimismo frente a la estabilidad democrática en la región y en general sus sociedades la valoran como un buen sistema, también es cierto que hay serias debilidades tanto a nivel nacional como internacional para su defensa y buen funcionamiento. 
A nivel nacional se sigue experimentando lo que se conoce como "Cansancio de la democracia", es decir aquellas conductas que no ayudan a su fortalecimiento: ciudadanos desinteresados lo cual es fácilmente medible en los altos índices de abstencionismo; partidos políticos cada vez más débiles y poco representativos; perdida de las ideologías, y con ello nos referimos al corpus de valores y principios que identifican las colectividades y que garantizaban propuestas y acuerdos programáticos y no orientados simplemente en alimentar burocracias y maquinarias políticas clientelares. Políticas asistencialistas que fortalecen los populismos y con ello la corrupción, mientras que debilitan los sanos controles políticos. A esto hay que sumarle un largo etcétera. ${ }^{15}$

A nivel internacional si bien se han creado organismos internacionales e instrumentos, tales como la "Carta Democrática Interamericana" de la OEA (2001), se ha experimentado dificultades a la hora de aplicarlos, pues generalmente prima el realismo político (cálculos en los equilibrios de poder) ${ }^{16}$, y así los compromisos adquiridos no pasan de ser declaraciones de buenas intenciones sin efectos prácticos y sin ninguna presión real para aquel que violente dichos principios ${ }^{17}$. El debilitamiento de la Verdad y el ascenso de los relativismos han llevado a que exista un gran temor a denunciar cuando una democracia se ha convertido sin más en una dictadura. Erradamente se cree que ser demócrata implica respetar absolutamente todas las posiciones como igualmente válidas y perder el norte de lo que está bien y lo que está mal, y por tanto tiende interpretarse que es democrático respetar que alguien pretenda perpetuarse en el poder, acaparar todos los poderes, censurar la prensa y tener presos políticos; se señala esto como una libertad de los pueblos a autodeterminarse olvidando que es justamente ese pueblo el que está secuestrado por unos grupos que se han tomado el poder y no le permiten expresarse libremente. De allí la importancia de recordar realmente en qué consiste una democracia, y por eso quisimos iniciar nuestra reflexión desde sus postulados fundamentales y no desde sus formas, pues no en pocas ocasiones han sido simples fachadas para legitimar dictaduras. ${ }^{18}$

15. "La convivencia democrática, que se afianzó después de Puebla, en algunos países se ha venido deteriorando, entre otros factores, por los siguientes: corrupción administrativa, distanciamientos de los liderazgos partidistas con relación a los intereses de las bases y las reales necesidades de la comunidad; vacíos programáticos y desatención de lo social y ético-cultural de parte de las organizaciones partidistas; gobiernos elegidos por el pueblo, pero no orientados eficazmente al bien común; mucho clientelismo político y populismo, pero poca participación". (Santo Domingo 192)

16. En Aparecida se reconoce que los Organismo internacionales hacen recomendaciones que no siempre están ajustados a criterios éticos (Cfr.75)

17. El Papa Francisco, aunque refiriéndose al tema ecológico, llamó la atención sobre este fenómeno "El siglo XXI, mientras mantiene un sistema de gobernanza propio de épocas pasadas, es escenario de un debilitamiento de poder de los Estados nacionales, sobre todo porque la dimensión económico-financiera, de características transnacionales, tiende a predominar sobre la política. En este contexto, se vuelve indispensable la maduración de instituciones internacionales más fuertes y eficazmente organizadas, con autoridades designadas equitativamente por acuerdo entre los gobiernos nacionales, y dotadas de poder para sancionar". (Laudato si 175)

18. "Hoy se tiende a afirmar que el agnosticismo y el relativismo escéptico son la filosofía y la actitud fundamental correspondientes a las formas políticas democráticas, y que cuantos están convencidos de conocer la verdad y se adhieren a ella con firmeza no son fiables desde el punto 
Habrá que tomar con seriedad las reflexiones del Papa Benedicto XVI cuando anima a una Caritas in Veritate "caridad en la verdad", en otras palabras que el amor (para el caso los discursos de apertura, tolerancia, pluralismo, diálogo, diplomacia, hermandad) no puede ser ciego o irreflexivo, no puede renunciar a la razón pues caería en mero sentimentalismo, discursos bonitos que pueden ocultar las más crueles realidades.

En Aparecida (2007), se reconoce que muchas cosas han cambiado gracias a la Globalización, sin embargo respecto a la política, en el discurso inaugural, Benedicto XVI advierte que a pesar de que en América Latina y El Caribe se ha evolucionado hacia la democracia se manifiesta que hay "motivos de preocupación ante formas de gobierno autoritarias o sujetas a ciertas ideologías que se creían superadas, y que no corresponden con la visión cristiana del hombre y de la sociedad".

Esta idea aparece reforzada en el numeral 74 donde a pesar de reconocer un progreso democrático en tanto lo electoral se subraya que existe la preocupación del "acelerado avance de diversas formas de regresión autoritaria por vía democrática que, en ciertas ocasiones, derivan en regímenes de corte neopopulista", lo que va emparentado con "el recrudecimiento de la corrupción en la sociedad y en el Estado, que involucra a los poderes legislativos y ejecutivos en todos sus niveles, y alcanza también al sistema judicial que, a menudo, inclina su juicio a favor de los poderosos y genera impunidad"(77).

Y es que justamente el neopopulismo es el más reciente problema en las democracias latinoamericanas, ha afectado con mayor rigor a Venezuela, Bolivia, Ecuador y Nicaragua bajo el llamado socialismo del siglo XXI, una "modalidad hasta ahora inédita de neocomunismo que cuenta con todo el apoyo de la Cuba castrista"19, que ya se ha hecho también sentir en otros países y en foros internacionales como la UNASUR, el Foro de São Paulo y el ALBA (Alianza Bolivariana para los Pueblos de Nuestra América).

El populismo tradicional consiste como lo explica el profesor Kurt Weyland en una "estrategia política mediante la cual un líder personalista busca o ejerce el poder gubernamental a partir del apoyo directo, inmediato y no institucionalizado de un gran número de seguidores no organizados"20, su forma de legitimación es carismática, apela a una comunicación emotiva, simple

de vista democrático, al no aceptar que la verdad sea determinada por la mayoría o que sea variable según los diversos equilibrios políticos. A este propósito, hay que observar que, si no existe una verdad última, la cual guía y orienta la acción política, entonces las ideas y las convicciones humanas pueden ser instrumentalizadas fácilmente para fines de poder. Una democracia sin valores se convierte con facilidad en un totalitarismo visible o encubierto, como demuestra la historia." (Centesimus Annus 46)

19. Apuleyo Mendoza, Plinio. Montaner Suris, Carlos Alberto. Vargas Llosa, Álvaro. Últimas noticias del nuevo idiota iberoamericano. Bogotá: Planeta, 2014. p.261

20. Citado en Ibíd. p. 261. 
que busca congraciarse con el "pueblo", tiende a presentar a la clase media y alta como si fueran una clase dominante, opresora y corrupta siguiendo el viejo esquema del marxismo. El neopopulismo por su parte recoge estos planteamientos, el líder sigue ubicándose por encima de las instituciones, las leyes y cree encarnar el sentir del pueblo y ser el único capaz de "salvarlo", de allí que apele con frecuencia a enemigos internos (la oposición) o externos (suele ser el "imperialismo estadounidense"), o a mitos fundacionales (como el bolivarianismo), para legitimar su discurso y buscar la unidad nacional a la que aspira. Se puede decir, en el campo económico, que "el reparto desenfrenado de dinero y prebendas lo conduce a nacionalizar recursos sin medir costos y a edificar un Estado empresario que atenta contra la libertad económica, al imponer controles de precios, aplicar cuotas de producción y consumo, y expropiar tierras e industrias"21, lo que en lugar de generar desarrollo termina por aumentar las conductas asistencialistas, los cordones de miseria, pues no se privilegia la eficiencia ni la sostenibilidad sino que el ingreso de las distintas empresas estatales se destinan a pagar cuotas políticas, por lo que aumenta la corrupción.

Una de las razones que explican la reaparición del populismo, tiene que ver con la debilidad de los partidos políticos que tuvieron en su momento mucha fuerza, cuya confianza se vio menguada justamente por la corrupción, al punto que la figura del político quedó desprestigiada y en la actualidad justamente empiezan a tener mayor fuerza personas que dicen no deberle nada a las "maquinarias", que hacen su labor de "forma independiente". Lo que tal vez se olvida es que los partidos políticos bien entendidos tienen una función que una persona en solitario no puede cumplir, y es que más allá de la representatividad y unidad en ideas, también existe una la labor de relevo que privilegia la institucionalidad, en otras palabras se trata de formar nuevas generaciones que puedan también liderar y no estar dependiendo exclusivamente de la figura de un solo líder.

Como lo explica Plinio Apuleyo Mendoza, Carlos Alberto Montaner y Álvaro Vargas Llosa, el balance que arroja hoy el neopopulismo en el continente es este:

“Un aparato productivo muy menoscabado; empresas estatales que arrojan perdidas millonarias; destrucción de fuentes de trabajo y empobrecimiento progresivo; una altísima inflación; una deuda pública hipertrofiada; una infraestructura en ruinas; un sector energético en crisis; y el deterioro creciente de las prestaciones sanitarias, educativas y otros servicios del Estado. Y, por si fuera poco, una alarmante inseguridad, nunca antes vista, y una innegable corrupción e incompetencia en el manejo de los asuntos públicos. La pobreza, aunque enmascarada con dádivas, sigue reinando en suburbios, cerros y zonas rurales." 22 
Se pone de manifiesto nuevamente la idea en la que hemos insistido que "no basta una democracia puramente formal, fundada en la limpieza de los procedimientos electorales, sino que es necesaria una democracia participativa y basada en la promoción y respeto de los derechos humanos. Una democracia sin valores, como los mencionados, se vuelve fácilmente una dictadura y termina traicionando al pueblo". (Aparecida 74)

Y cuando hablamos de participación debemos hacer nuestras las palabras del Papa Francisco en su Encíclica Laudato Si' "La participación requiere que todos sean adecuadamente informados de los diversos aspectos y de los diferentes riesgos y posibilidades, y no se reduce a la decisión inicial sobre un proyecto, sino que implica también acciones de seguimiento o monitorización constante. Hace falta sinceridad y verdad en las discusiones científicas y políticas, sin reducirse a considerar qué está permitido o no por la legislación.” (183), la responsabilidad exige pensar también en el futuro, de allí que se deba apuntar a políticas que piensen cada vez más en el Estado y en la Región, que finalmente es lo que permanece y no simplemente en intereses cortoplacistas del gobierno de turno. El Papa agrega, "la grandeza política se muestra cuando, en momentos difíciles, se obra por grandes principios y pensando en el bien común a largo plazo. Al poder político le cuesta mucho asumir este deber en un proyecto de nación.” (178)

\section{Conclusión}

El llamado que se hace es a recuperar el sentido mismo de la comunidad política, es decir, recordar la razón del por qué los seres humanos somos sociables, por qué buscamos estar con otros y en esta medida descubrirnos menesterosos (necesitados); en otro sentido, la invitación es a reconocer que hacemos más y somos más cuando no estamos solos, cuando contamos con los otros y juntos buscamos el bien común ${ }^{23}$. Las distintas comunidades políticas surgen de ese interés, y aunque tienen diversas formas de organizarse y también hay relaciones conflictivas no solo entre ellas sino también al interno, hay un "pegamento" que las une y es de fondo la certeza de estar mejor con los otros que si viviésemos solos. Pero esta certeza necesita también un orden y desde allí que la democracia ${ }^{24}$ parece ser el mejor sistema, pues se muestra propicio para poner en diálogo las diversas posturas que se tienen, no solo para que unas triunfen sobre otras, sino también para buscar perfeccionarlas entre todos, buscar soluciones sobre la base de la racionalidad y del respeto por la diferencia.

23. "El bien común abarca el conjunto de aquellas condiciones de vida social con las cuales los hombres, las familias y las asociaciones pueden lograr con mayor plenitud y facilidad su propia perfección." (GS74)

24. "Pero son muchos y diferentes los hombres que se encuentran en una comunidad política, y pueden con todo derecho inclinarse hacia soluciones diferentes. A fin de que, por la pluralidad de pareceres, no perezca la comunidad política, es indispensable una autoridad que dirija la acción de todos hacia el bien común no mecánica o despóticamente, sino obrando principalmente como una fuerza moral, que se basa en la libertad y en el sentido de responsabilidad de cada uno." (GS74) 
Así mismo se hace un llamado a la responsabilidad, que apunta directamente al compromiso que cada ciudadano debe asumir en una democracia ${ }^{25}$. No es que los demás sistemas no lo exijan, es que al afirmar que la soberanía reside en el pueblo se hace imperativo el compromiso de este para ejercerla y para ello debe formarse. La actitud de ninguna manera puede ser pasiva y debe estar alerta a los posibles abusos para tomar los correctivos correspondientes ${ }^{26}$, pero así mismo, se recuerda que tampoco se deben dar abusos de parte de los ciudadanos hacia el Estado pues claramente es una situación que va en detrimento de los que realmente están necesitados ${ }^{27}$.

En suma, como lo expresa la Gaudium et Spes “La mejor manera de llegar a una política auténticamente humana es fomentar el sentido interior de la justicia, de la benevolencia y del servicio al bien común y robustecer las convicciones fundamentales en lo que toca a la naturaleza verdadera de la comunidad política y al fin, recto ejercicio y límites de los poderes públicos.” (GS73)

\section{Bibliografía}

Constitución Pastoral Gaudium et Spes (Concilio Vaticano II). 1965. http://www.vatican. va/archive/hist_councils/ii_vatican_council/documents/vat-ii_const_19651207_ gaudium-et-spes_sp.html

Pablo VI. Carta Encíclica Populorum Progressio. 1967. http://w2.vatican.va/content/paulvi/es/encyclicals/documents/hf_p-vi_enc_26031967_populorum.html

Juan Pablo II. Carta Encíclica Sollicitudo Rei Socialis. 1987. http: / /w2.vatican.va/content/ john-paul-ii/es/encyclicals/documents/hf_jp-ii_enc_30121987_sollicitudo-reisocialis.html

25. "Hay que prestar gran atención a la educación cívica y política, que hoy día es particularmente necesaria para el pueblo, y, sobre todo para la juventud, a fin de que todos los ciudadanos puedan cumplir su misión en la vida de la comunidad política. Quienes son o pueden llegar a ser capaces de ejercer este arte tan difícil y tan noble que es la política, prepárense para ella y procuren ejercitarla con olvido del propio interés y de toda ganancia venal. Luchen con integridad moral y con prudencia contra la injusticia y la opresión, contra la intolerancia y el absolutismo de un solo hombre o de un solo partido político; conságrense con sinceridad y rectitud, más aún, con caridad y fortaleza política, al servicio de todos." (GS 75)

En el documento conclusivo de Medellín se repite esta idea "La carencia de una conciencia política en nuestros países hace imprescindible la acción educadora de la Iglesia, con objeto de que los cristianos consideren su participación en la vida política de la Nación como un deber de conciencia y como el ejercicio de la caridad, en su sentido más noble y eficaz para la vida de la comunidad." (Medellín 16)

26. "Pero cuando la autoridad pública, rebasando su competencia, oprime a los ciudadanos, éstos no deben rehuir las exigencias objetivas del bien común; les es lícito, sin embargo, defender sus derechos y los de sus conciudadanos contra el abuso de tal autoridad, guardando los límites que señala la ley natural y evangélica."(GS 74)

27. "Los ciudadanos por su parte, individual o colectivamente, eviten atribuir a la autoridad política todo poder excesivo y no pidan al Estado de manera inoportuna ventajas o favores excesivos, con riesgo de disminuir la responsabilidad de las personas, de las familias y de las agrupaciones sociales." (GS75) 
Juan Pablo II. Carta Encíclica Centesimus Annus. 1991. http://w2.vatican.va/content/ john-paul-ii/es/encyclicals/documents/hf_jp-ii_enc_01051991_centesimusannus.html

Benedicto XVI. Carta Encíclica Caritas In Veritate. 2009. http://w2.vatican.va/content/ benedict-xvi/es/encyclicals/documents/hf_ben-xvi_enc_20090629_caritas-inveritate.html

Francisco. Carta Encíclica Laudato Si'. 2015. http://w2.vatican.va/content/francesco/ es/encyclicals/documents/papa-francesco_20150524_enciclica-laudato-si.html

Documento conclusivo de la II Conferencia Episcopal Latinoamericana. Medellín. 1968 http://www.celam.org/doc_conferencias/Documento_Conclusivo_Medellin.pdf

Documento conclusivo de la III Conferencia Episcopal Latinoamericana. Puebla. 1979 http://www.celam.org/doc_conferencias/Documento_Conclusivo_Puebla.pdf

Documento conclusivo de la IV Conferencia Episcopal Latinoamericana. Santo Domingo.1992 http://www.celam.org/doc_conferencias/Documento_Conclusivo_Santo_Domingo.pdf

Documento conclusivo de la V Conferencia Episcopal Latinoamericana. Aparecida. 2007 http://www.celam.org/doc_conferencias/Documento_Conclusivo_Aparecida.pdf

Apuleyo Mendoza, Plinio. Montaner Suris, Carlos Alberto. Vargas Llosa, Álvaro. Últimas noticias del nuevo idiota iberoamericano. Bogotá: Planeta, 2014.

Barbé, Esther. Relaciones Internacionales. Madrid: Tecnos, 2007.

Campillo Vélez, Beatriz Eugenia. "El desafío de la verdad en la construcción de la civilización de la vida”. "EL RESPETO A LA VIDA: Un camino para la paz". Memorias congreso internacional de la Fundación Vaticana Joseph Ratzinger - Benedicto XVI. Medellín: Universidad Pontificia Bolivariana y Editorial San Pablo, 2014.

Delgado, Miguel M. (Director). Película: “Su excelencia”. Productora: Posa Films. México: 1967.

Dinges, John. Operación cóndor: una década de terrorismo internacional en el cono sur. Santiago: Ediciones B Chile S.A., 2004.

Thesing, Josef. Democracia y Estado de Derecho en América Latina. En: La cuestión social, México, Instituto Mexicano de Doctrina Social Cristiana, año 8, no. 1 (ene.-mar., 2000), pp. 65-68. Recuperado de: http://media.wix.com/ugd/768ef7_0171f2f33 49b47f5b36e77f8b5e84c2e.pdf

Leal Buitrago, Francisco. La doctrina de seguridad nacional: materialización de la guerra fría en américa del sur. Revista de Estudios Sociales, no. 15, junio de 2003, pp.74-87.

Patiño Aristizábal, Luis Guillermo. "El neopopulismo en el contexto de la democracia latinoamericana". Revista Facultad de Derecho y Ciencias Políticas. Vol. 37, No. 106 / p. 239 - 261. Medellín - Colombia. Enero-Junio de 2007.

Suárez Molano, José Olimpo. Syllabus sobre filosofía política. Medellín: Editorial UPB, 2004.

Vargas Llosa, Álvaro. "Consecuencias: América Latina al descubierto" (indigenismo, dictadura, populismo e imperialismo). National Geographic Channel, 2008. 